Received Date : 17-Jun-2015

Accepted Date : 23-Nov-2015

Article type : Primary Research Articles

\title{
Modelling the introduction and spread of non-native species: International trade and climate change drive ragweed invasion
}

Running head: Modelling non-native transport and spread

List of authors: Daniel S. Chapman ${ }^{1}$, László Makra ${ }^{2}$, Roberto Albertini ${ }^{3}$, Maira Bonini ${ }^{4}$, Anna Páldy ${ }^{5}$, Victoria Rodinkova ${ }^{6}$, Branko Šikoparija ${ }^{7}$, Elżbieta Weryszko-Chmielewska ${ }^{8}$ \& James M. Bullock $^{9}$

\section{Addresses:}

${ }^{1}$ NERC Centre for Ecology \& Hydrology, Bush Estate, Edinburgh EH26 0QB, UK.

${ }^{2}$ Institute of Economics and Rural Development, Faculty of Agriculture, University of Szeged, 6800 Hódmezővásárhely, Andrássy út 15, Hungary.

${ }^{3}$ Department of Clinical and Experimental Medicine, University of Parma, Italy.

${ }^{4}$ Department of Medical Prevention, Public Health, Local Health Authority of Milan 1, Parabiago (Mi), Italy.

${ }^{5}$ National Institute of Environmental Health, Department of Aerobiological Monitoring, Gyáli út 2-6, 1097 Budapest, Hungary.

${ }^{6}$ Vinnitsa National Pirogov Memorial Medical University, Vinnitsa, Ukraine.

BioSense Institute - Research Institute for Information Technologies in Biosystems, University of Novi Sad, Novi Sad, Serbia.

This is the peer reviewed version of the following article: Chapman, D. S., Makra, L. , Albertini, R. , Bonini, M. , Páldy, A. , Rodinkova, V., Šikoparija, B. , Weryszko - Chmielewska, E. and Bullock, J. M. (2016), Modelling the introduction and spread of non - native species: international trade and climate change drive ragweed invasion. Global Change Biol, 22: 3067-3079., which has been published in final form at https://doi.org/10.1111/gcb.13220. This article may be used for noncommercial purposes in accordance with Wiley Terms and Conditions for self-archiving. 
${ }^{9}$ NERC Centre for Ecology \& Hydrology, Maclean Building, Benson Lane, Crowmarsh Gifford, Wallingford OX10 8BB, UK.

Corresponding author: Daniel Chapman; tel: +44 (0)131 4458549; dcha@ceh.ac.uk

Keywords: Invasive alien species, introduced species, trade pathway model, biosecurity, plant health, dispersal, colonisation, bioeconomic model.

Running-title: Integrating introduction and spread in the modelling of invasion

\section{Abstract}

Biological invasions are a major driver of global change, for which models can attribute causes, assess impacts and guide management. However, invasion models typically focus on spread from known introduction points or non-native distributions and ignore the transport processes by which species arrive. Here, we developed a simulation model to understand and describe plant invasion at a continental scale, integrating repeated transport through trade pathways, unintentional release events and the population dynamics and local anthropogenic dispersal that drive subsequent spread. We used the model to simulate the invasion of Europe by common ragweed (Ambrosia artemisiifolia), a globally-invasive plant that causes serious harm as an aeroallergen and crop weed. Simulations starting in 1950 accurately reproduced ragweed's current distribution, including the presence of records in climatically-unsuitable areas as a result of repeated introduction. Further, the model outputs were strongly correlated to spatial and temporal patterns of ragweed pollen concentrations, which are fully independent of the calibration data. The model suggests that recent trends for warmer summers and increased volumes of international trade have accelerated the ragweed invasion. For the latter, long distance dispersal because of trade within the invaded continent is highlighted as a key invasion process, in addition to import from the native range. Biosecurity simulations, whereby transport through trade pathways is halted, showed that effective control is only achieved by early action 
targeting all relevant pathways. We conclude that invasion models would benefit from integrating introduction processes (transport and release) with spread dynamics, to better represent propagule pressure from native sources as well as mechanisms for long-distance dispersal within invaded continents. Ultimately, such integration may facilitate better prediction of spatial and temporal variation in invasion risk and provide useful guidance for management strategies to reduce the impacts of invasion.

\section{Introduction}

Human transport of species beyond their native ranges and their subsequent release, establishment and spread is one of the major components of global environmental change (Mack et al., 2000). Invasive non-native species are important drivers of biodiversity loss, alteration of ecosystem function and degradation of ecosystem services (Vilà et al., 2011). Particular non-native species also directly impact human wellbeing, for example being detrimental to public health or agriculture (Pyšek \& Richardson, 2010, Smith et al., 2013). As such, there has been considerable interest in developing models that capture our understanding of invasion (Gallien et al., 2010, Yemshanov et al., 2009). Part of the motivation is to predict ongoing spread to anticipate ecological and economic costs of invasion (Hamaoui-Laguel et al., 2015). Models can also provide useful guidance for planning management or control strategies to reduce these impacts (Richter et al., 2013b).

In reviewing biological invasion models, Gallien et al. (2010) distinguished between two major approaches. The first comprises broad-scale screening with species distribution models. These statistical niche models represent how species' occupancy probability responds to climate and other factors and predict where the environment is suited to invasion (Thuiller et al., 2005). The second approach comprises more strongly process-based models for invasion dynamics. These are based on population growth and dispersal - the two major demographic processes influencing invasion (Neubert \& Caswell, 2000). Recently, 'hybrid models' have been developed to capitalise on the strengths of both approaches be representing the effects of environmental heterogeneity on the 
demographic processes underlying invasion (Merow et al., 2011). However, despite much progress, these models are still typically restricted to spread from a known location of entry or alreadyestablished non-native distribution and ignore anthropogenic transport, release or introduction processes (Yemshanov et al., 2009).

We argue that a greater integration of introduction and spread models is needed for several reasons. Firstly, repeated introduction to multiple areas is a feature of many invasions (Gaudeul et al., 2011) and can increase genetic diversity, adaptive potential and invasion success (Dlugosch \& Parker, 2008). Multiple introductions should also increase the rate that non-native species with limited dispersal abilities can track and respond to climatic and other environmental change. Furthermore, suitable areas may remain uninvaded if they receive little anthropogenic propagule pressure for introduction, while high propagule pressure may indicate apparent invasion in areas of low suitability (Lockwood et al., 2005). Both circumstances cause mismatch between the species' observed invasive distribution and its true habitat or climatic niche, which will mislead models that do not account for such processes (Chapman et al., 2014). Finally, propagule pressure may change as a direct consequence of invasion. As a species establishes in part of an invaded continent, the same transport mechanism that imported the species from the native range may begin to operate within the invaded continent. Therefore anthropogenic transport processes may also become an important source of longdistance dispersal within an invaded region.

Given the need for better model integration, how might this be achieved? Many existing 'hybrid models' for invasion (Gallien et al., 2010) comprise simulation models with stochastic dispersal components representing the advent of new invasive populations via dispersal from established populations (Merow et al., 2011). In general, these should be well suited for the inclusion of new algorithms for stochastic introduction or entry events, which can readily be implemented alongside algorithms defining population growth and dispersal. Yemshanov et al. (2009) proposed that an entry sub-model should represent the likely transport pathways for the invading organism and the resulting spatio-temporal variation in introduction or entry probability in the modelled region. International trade is the principal transport mechanism for many, if not most, non-native species (Bradley et al., 
2011, Hulme, 2009) and so economic data on networks of commodity movements between regions or countries may be used to define propagule pressure from transport pathways (Seebens et al., 2013). Such models may also have potential to consider how biosecurity measures during transport (e.g. border inspections, commodity treatments etc.) affect the resulting probabilities of species arrival.

Here, our aim is to develop a simulation model that integrates the accidental transport, establishment and spread of common ragweed (Ambrosia artemisiifolia L.) in Europe. Native to North America, ragweed has invaded human-modified habitat in Europe, Asia, Australia and South America (Bullock et al., 2012, Essl et al., 2015). Where large populations establish, ragweed is a serious agricultural weed and severely impacts public health via highly allergenic pollen (Prank et al., 2013, Smith et al., 2013). Ragweed seed is a common contaminant of internationally traded planting and bird seed commodities (Bullock et al., 2012, EFSA Panel on Contaminants in the Food Chain (CONTAM) et al., 2010) and historical and genetic analyses have identified strong signatures of repeated introduction to Europe (Chauvel et al., 2006, Gaudeul et al., 2011). As with many invasive species (e.g. Petitpierre et al., 2012) another key mediator of ragweed invasion is climate, and there is concern that climatic warming will allow expansion of ragweed's invasive distribution and impacts (Bullock et al., 2012, Chapman et al., 2014, Cunze et al., 2013, Hamaoui-Laguel et al., 2015). Therefore, we developed the model to integrate transport and release through seed trade pathways with climatic effects on population growth. This allowed us to simulate the interacting effects of recent trade patterns, climate change and biosecurity measures (which involve preventative steps to reduce the risk of accidental transport and release to the wild of ragweed) in mediating the invasion.

This article is protected by copyright. All rights reserved. 


\section{Materials and methods}

\section{Model overview}

We developed a simple model to simulate ragweed invasion of Europe through repeated transport on trade pathways, unintentional release events and the population dynamics and local anthropogenic dispersal that drive subsequent spread (see Fig. S1 and S2 for overviews). Importation from the native range and transport from already-invaded regions was modelled stochastically, based on volumes of international bird and planting seed trade from the native and invaded countries. Establishment and spread were modelled through a combination of deterministic adult and seedbank population dynamics and stochastic neighbourhood seed dispersal. The population dynamics were forced by land cover and inter-annual variation in climate and trade. The model was calibrated against the current invasion, validated against independent data and then used to simulate the impact of hypothetical historical biosecurity scenarios. The model contained several simplifying assumptions, which reflect the lack of more detailed information on certain processes, but also the need to maintain tractability and avoid excessive parameterisation (Grimm et al., 2005). We specify these below and address them further in the Discussion.

\section{Ragweed transport model}

Imports of bird seed and planting seed (for sowing crops) are known to be the principal pathways for ragweed transport (Bullock et al., 2012, Chauvel et al., 2006, EFSA Panel on Contaminants in the Food Chain (CONTAM) et al., 2010). In the absence of more detailed data, our model assumed that exported seed is gathered evenly across cropland in the exporter country, transported through international trade networks and then distributed evenly across the importer country's urban areas (for bird seed) or cropland (for planting seed). These are the principal habitats for ragweed invasion (Bullock et al., 2012). Therefore, we modelled transported propagule pressure as a function of trade flows and ragweed abundance in cropland in the source countries. Exporter sources comprised the USA - capturing nearly all of ragweed's native range and all potentially-invaded European countries.

This article is protected by copyright. All rights reserved. 
For the bird seed pathway, we were able to obtain relevant trade flow data in the form of exports from the USA to Europe (see below). Therefore we modelled the bird seed transport pathway only from the native range. The model assumes that bird seed is only used within urban areas, where the great majority of consumers live. Using the cumulative distribution function of the exponential distribution, a simple survival function for constant risk of importation per unit of imported bird seed over one year, we formulate the probability of transport and release with bird seed $\left(P_{i, t}^{\text {bind }}\right)$ to grid cell $i$ in year $t$ as:

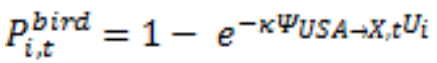

where $\Psi_{U S A \rightarrow X_{n} t}$ is the bird seed import rate (tonnes $\mathrm{km}^{-2}$ ) from the USA to urban land in $X$ (the country to which $i$ belongs) in year $t, U_{i}$ is the proportion urban cover in $i$ and $\kappa$ is a scaling parameter. The quantity $\kappa \Psi_{U S A \rightarrow X_{t} t} U_{i}$ is the hazard function for no introduction occurring in that grid cell and year.

For the planting seed pathway we obtained data on seed imports from the native range (USA) as well as bilateral trade flows within Europe, allowing us to use a similar model for importation from the native range as well as transport from already-invaded parts of Europe. Because the ragweed population of European countries changed over time, we included a term representing the relative ragweed contamination of planting seed gathered and exported from each country, defined here as the amount of ragweed seed per unit area of cropland. For the USA this was a constant model parameter, $\Omega_{U S A}$. For European countries, the contamination for country $X$ in year $t, \Omega_{X, t}$ depends on its current level of cropland ragweed infestation,

$$
\Omega_{X_{n},}=\frac{\sum_{j \in X} N_{j, t-1} F_{j, t-1} C_{j} /\left(C_{j}+U_{j}\right)}{\sum_{j \in X} C_{j}}
$$

where $j$ indexes the grid cells within country $X . N$ is the adult ragweed population size and $F$ is its fecundity (see below), so their product represents seed production. $C$ is the proportion cover of cropland, so that $C+U$ is the invadable proportion of the grid cell (Richter et al., 2013b). We 
assumed cropland and urban areas support similar ragweed populations. Therefore the numerator sums ragweed seed production from infested cropland, assuming an even distribution between crops and urban, and the denominator is the total cropland in the country (in grid cells).

The total propagule pressure from transport of planting seed into country $X\left(K_{X, t}\right)$ was modelled as the product of the contamination index and planting seed import rate $\theta_{Y \rightarrow X}$ (tonnes $\mathrm{km}^{-2}$ cropland), summed over all source countries modelled (USA and Europe, indexed by $Y$ ):

$K_{X_{t} t}=\sum_{Y \neq X} \Omega_{Y, t} \Theta_{Y \rightarrow X_{2} t}$

Finally the probability of colonisation from planting seed $\left(P_{i, t}^{\text {planting }}\right)$ to a grid cell $i$ in year $t$ was formulated equivalently to the model for the bird seed pathway:

$P_{i, t}^{\text {planting }}=1-e^{-v K_{X_{t}} C_{i}}$

where $v$ is a scaling rate parameter for the planting seed pathway. Note that it is straightforward to calculate $P_{i, t}^{\text {planting }}$ arising from either native or invaded propagule pressure to contrast the importance of both types of transport.

The combined probability of a new population arising through both trade pathways is therefore:

$P_{i, t}^{\text {trade }}=1-\left(1-P_{i, t}^{\text {bird }}\right)\left(1-P_{i_{2}, t}^{\text {planting }}\right)$

The model requires input data on land cover and bird and planting seed trade flows. Gridded land cover was taken from the Global Agro-Ecological Zones portal (Fischer et al., 2012). Bilateral trade data was obtained from the Global Agricultural Trade System (http://apps.fas.usda.gov/gats/default.aspx) (Fig. 1). Seed exports from the USA to each European country were available for 1991-2010 for bird seed (commodity 1206000090, sunflower seed excluding human use) and for 1967-2010 for planting seed (aggregate group 0120AT). Bilateral 
import volumes of planting seed for European countries were obtained for 1992-2010 (older data are available, but are incomplete). Prior to the changed status of certain countries (former USSR, Yugoslavia and Czechoslovakia), import rates of the former country were applied to all modern-day constituents. To account for incomplete temporal coverage of the trade data during simulations, we randomly sampled from the first ten years of trade data to simulate years prior to the beginning of the time series.

\section{Invasive spread model}

The spread model combines deterministic population dynamics with stochastic dispersal over a discrete annual time step. The first computation in each year $t$ is establishment of the adult population $N$ from the seedbank $B$ in each grid cell, indexed by $i$ :

$N_{i, t}=H_{i}\left(1-e^{-\lambda B_{i_{i}, t-1}-\delta_{i, t}}\right)$

where $H_{i}=C_{i}+U_{i}$ and represents the proportion invadable and $\lambda$ scales the increase in establishment of adults with the seedbank density. $N$ was specified with the general form of $1-e^{-x}$, which increases asymptotically from 0 and 1 with increasing values of $x$. Therefore $N$ represents the proportion of the grid cell infested by ragweed, i.e. it is an infested area and not strictly population size, and is limited in the model by a small seedbank. Establishment from transported or dispersed seeds is accounted for by the stochastic binary variable $\delta$, which is set to 0 if there is no transport or dispersal into the grid cell or to a small value $(\beta=0.0001)$ if immigration occurs from either process.

Next, we compute the change in relative seedbank density $B$, accounting for its persistence at rate $\alpha$ and input of new seed from the adult population:

$B_{i, t}=\left\{\begin{array}{cl}\alpha B_{i, t-1}+\frac{N_{i, t} F_{i, t}}{H_{i}} & \text { if } B_{t}>\beta / 4 \\ 0 & \text { if } B_{t} \leq \beta / 4\end{array}\right.$ 
Seedbank addition from the adult population is in proportion to a fecundity index $F$, depending on the climate (see below). Note that we divide by $H$, so $B$ represents the seedbank density within the invaded part of the grid cell. This reflects the assumption that ragweed's extremely limited primary dispersal ability (Bassett \& Crompton, 1975) means nearly all seeds are deposited within the already invaded area, and means the maximum population growth rate is independent of $H$. We assume extinction when $B$ falls below $\beta / 4$, preventing persistence of tiny seedbanks in highly unsuitable grid cells.

The fecundity index $F$ captures the climatic niche of ragweed. We specified fecundity limitation by warm winter temperature, cool summer temperature and low summer moisture availability (Essl et al., 2015). Ragweed seeds require chilling to break dormancy (Willemsen, 1975) so warm winters should delay germination, causing adult plants to be small and of low fecundity. Low summer temperature retards seed maturation and is considered an important determinant of ragweed's range (Chapman et al., 2014, Reznik, 2009). Drought during the growing season affects ragweed survival (Hodgins \& Rieseberg, 2011) and limits colonisation of dry environments (Reznik, 2009, Storkey et al., 2014). Therefore, $F$ was modelled with logistic functions for winter temperature $W$ (coldest mean monthly temperature from January to March - the time of seed stratification), summer temperature $S$ (mean monthly temperature from July to September - the time of flower and seed maturation) and moisture availability $M$ (ratio of total precipitation to potential evapotranspiration, estimated following Hargreaves et al. (1985), from June to August - the period of maximal growth and drought stress):

$F_{i, t}=\frac{1}{1+e^{-b_{W}\left(W_{i, t}-a_{W}\right)}} \frac{1}{1+e^{-b_{S}\left(S_{i, t}-a_{S}\right)}} \frac{1}{1+e^{-b_{M}\left(M_{i, t}-a_{M}\right)}}$

Parameters $a$ and $b$ are inflexions and slopes, respectively. The climatic variables $W, S$, and $M$ were derived from gridded monthly temperature and precipitation data for each year between 1950 and 2010 from the E-OBS database (Haylock et al., 2008). Some parts of Europe had missing data in the earlier of these years, which we filled with their average values over the whole time period.

This article is protected by copyright. All rights reserved. 
Ragweed long-distance seed dispersal between neighbouring populations at this scale is mainly anthropogenic, and caused by movements of machinery and soil (Bullock et al., 2012). In a previous study of spread in Austria this was modelled with a power law kernel (Richter et al., 2013b) which we used here to ensure realistic spread rates. Dispersal pressure $J$ was calculated by summing seed production in the previous year (product of adult infestation $N$ and fecundity $F$ ) in a set of neighbouring cells $\Lambda_{i}$, downweighted by their distance from the focal cell ( $d \mathrm{~km}$ ) according to the dispersal kernel $g$ :

$$
\begin{gathered}
I_{i, t}=\sum_{j \in \Lambda_{i}} N_{j, t-1} F_{j, t-1} g\left(d_{i j}\right) \\
g\left(d_{i j}\right)=\left(\frac{100}{35}\right)^{2}\left(\frac{d_{i j}}{d_{0}}\right)^{-\gamma}
\end{gathered}
$$

The parameters of the kernel $g$ were fixed at values fitted in the previous study: $d_{0}=0.63 \mathrm{~km}$ and $\gamma=2.02$ (Richter et al., 2013b), but re-scaled by the squared ratio of grid cell surface areas in both studies (100/35). Rescaling approximately corrects for the scale-dependence of emigration and immigration (Chipperfield et al., 2011). To improve computational efficiency, the dispersal neighbourhood $\Lambda$ only contained grid cells within $500 \mathrm{~km}$ of the focal cell, at which distance dispersal is extremely rare $\left(g=1.1 \times 10^{-5}\right)$.

Using an equivalent model for dispersal through trade, the seed dispersal probability into the grid cell increased with $J$ scaled by the parameter $\mu$ :

$P_{i, t}^{\text {dispersal }}=1-e^{-\mu \int_{i, t}}$

\section{Model calibration}

The model was calibrated or fitted to the current distribution of ragweed, using a pattern-oriented approach related to the rejection sampling used in Approximate Bayesian Computation (Beaumont, 2010). The distribution was constructed on a $10 \times 10 \mathrm{~km}$ grid with the European Terrestrial Reference System 1989 Lambert Azimuthal Equal Area projection (Fig. 2). An equal area projection avoids 
increases in grid cell area at high latitude that could confound the modelled dynamics. The primary source was the database of occurrence records from 1991-2010 compiled by Bullock et al. (2012) and updated by Chapman et al. (2014). Underlying this presence map is massive variation in population size, clearly evidenced through pollen monitoring (Prank et al., 2013, Skjøth et al., 2013) and allergy reports (Déchamp et al., 2009). To represent this, we assigned records as representing large and damaging versus small and casual populations. For France, this was achieved using high quality records differentiating heavily and lightly invaded locations (Petermann, 2011). For the Pannonian Plain, known to be the most invaded region in the EU (Smith et al., 2013), 'region grouping' on the presence records was used to assign all records connected to the Pannonian region as 'large' populations. This may have overestimated ragweed invasion at the periphery of the group but better data were not available. Cruder polygons depicting heavily or lightly invaded regions in Romania, Ukraine, Moldova and Russia were obtained from published sources to fill major gaps in the distribution (Afonin et al., 2008, Hodisan, 2011). For Italy, the main data source was ragweed populations recently surveyed for the newly invasive beetle Ophraella communa (Müller-Schärer $e t$ al., 2014). All these records are from the only region of Italy with high pollen counts (Smith et al., 2013), so we assumed they represent large populations. We consider the resulting map to be the best available high-resolution information on ragweed's distribution at the European scale (Fig. 2). However, for our analysis we differentiated between countries where we considered ragweed was well recorded and those where recording was less reliable, consisting of regional polygons or sparse records (see Chapman et al., 2014).

For calibration, we defined uniform ranges for the 12 free parameters (Table 1), based on plausible biological limits and preliminary model simulations, and randomly drew 10000 individual parameterisations. Five replicate invasions were simulated with each parameterisation from 19502010, and the mean adult infestation in 2010 was compared to the observed distribution. Rather than identify a single best parameterisation we instead averaged over the top $50(0.5 \%)$ parameterisations, to account for parameter uncertainty and the stochasticity in individual model runs. To quantify model fit, we calculated the sum of squares difference between the locations of large ragweed populations 
(coded large $=1$, other $=0$ ) and the simulated population size in 2010 (Gilbert et al., 2004). We only used the 'large' populations, since we were only concerned with accurate prediction of damaging invasive populations and wanted to ensure the simulated state of invasion by 2010 approximately matched the current extent of observed invasion. Because of variation in ragweed recording, we calculated separate sum of squares values for the regions where ragweed was considered as wellrecorded ('good data') and those regions where we considered otherwise ('poor data'), based on the quality and quantity of contributing data obtained for each country (Bullock et al., 2012). Their weighted mean was used as an overall measure of performance, giving treble weighting to the 'good data' area.

Simulations were initiated in 1950 with a mainly ragweed-free Europe. Although ragweed was recorded in Europe since the $19^{\text {th }}$ century, most range expansion has occurred since 1950 (Bullock et al., 2012, Csontos et al., 2010). We lack good information on the status of earlier populations and so preferred to simulate invasion from an empty map. The exception to this was southern Russia, where as early as 1940 there was major invasion throughout Stavropol and Krasnodar provinces (Reznik, 2009). To account for this, simulations were initiated with a moderate seedbank $(B=1)$ in grid cells in both provinces, from which populations could grow or decline according to their suitability for ragweed.

\section{Model validation}

To validate the model outputs against data that are independent of the distribution data used for model calibration, we obtained total annual aerial Ambrosia pollen counts from monitoring stations across Europe. Daily pollen counts for each year between 1995 and 2010 were obtained from 56 stations in Bulgaria France, Hungary, Italy, Poland, Serbia and Switzerland. Pollen counts for 2010 were also obtained for 139 stations, extending spatial coverage into Croatia, Romania, Russia, Slovakia, Slovenia and Ukraine. For quality assurance, we calculated the proportion of days that were missing data within the ragweed pollen season for each station-year combination. If more than $25 \%$ of days were missing data, that station-year combination was excluded. Otherwise, the pollen count over the 
non-missing days was corrected by dividing by the proportion of days with data. This procedure meant that $42.7 \%$ of the $1995-2010$ data and $33.8 \%$ of the 2010 data were excluded. The reduced dataset represented 47 stations for the 1995-2010 data and 92 stations from 2010 (see map in Fig. S3).

Pollen production, emission and long range transport were not represented in our model and have an impact on the pollen counts recorded at the stations (Hamaoui-Laguel et al., 2015, Prank et al., 2013). Although the majority of ragweed pollen is deposited close to its source, about $1 \%$ of released pollen remains airborne for $>1 \mathrm{~km}$ from the source edge (Raynor et al., 1970). Consequently, we expected that the simulated ragweed population size and fecundity in the landscape around each station should be correlated to the station data, as is assumed when estimating ragweed pollen source inventories (Skjøth et al., 2010, Thibaudon et al., 2014). Therefore we compared the pollen counts with the mean simulated population-fecundity (product of adult population and fecundity, $N F$ ) in the grid cell in which each station was located. Results were qualitatively identical if $N$ was used as the comparator rather than $N F$.

\section{Hypothetical biosecurity simulations}

The model does not account for biosecurity measures, such as seed certification regulations (Winge, 2012), that may have reduced ragweed introduction pressure over time. Because of this, and also to establish the general potential for biosecurity to limit invasive spread, we ran hypothetical historical biosecurity simulations with the calibrated models. For this, we halted the process of transport and release through trade after various years during the simulations, and compared the resulting population sizes in 2010 to those produced by the default version of the model. We ran two alternative biosecurity scenarios: (1) biosecurity applies to both the planting seed and bird seed pathway, and (2) biosecurity applies only to the planting seed pathway. The latter was considered because there is evidence of widespread ragweed contamination of bird seed throughout the simulation period (EFSA Panel on Contaminants in the Food Chain (CONTAM) et al., 2010), while levels of compliance to European Directives on planting seed certification have apparently been high (Winge, 2012). 


\section{Results}

\section{Model calibration}

When calibrated by averaging over the top $0.5 \%$ of random candidate parameterisations, the model outputs showed a very strong correspondence to the observed distribution of large invasive populations (Figs. 2, 3a). To quantify model accuracy, we applied the area under the receiver operating characteristic curve (AUC) statistic. Because AUC is not sensitive to rank-preserving transformations of the model prediction, such as a function translating predicted population sizes into detection probabilities, it is an appropriate measure of the models' ability to discriminate various subsets of the data (Lobo et al., 2008). Across the whole modelled domain, the discrimination ability (AUC) between all ragweed records and grid cells without records ('absences') was AUC $=0.892$, meaning there was an $89.2 \%$ probability that a randomly selected observed presence has a higher modelled population size than a randomly selected 'absence'. The discrimination between grid cells with records of damagingly invasive versus casual or small populations (see Fig. 2) was AUC $=0.820$ and the discrimination between casual or small records and 'absences' was AUC $=0.835$.

The most important parameters for calibration were those defining niche responses to summer temperature and moisture, adult establishment from the seedbank and dispersal from neighbouring populations (Table 1). In the simulations, ongoing spread in heavily invaded regions was primarily caused by dispersal from neighbouring populations rather than transport through international trade networks (Fig. 3c-f, Fig. 4d). By contrast, small and casual populations tended to occur in areas where the model predicted high propagule pressure through trade but were rarely reached by neighbourhood dispersal (Fig. 3c-e, Fig. 4d). Imports from North America were primarily affecting central and western Europe, while seed imports from already-invaded countries were relatively more important for spread into north-eastern Europe (Fig. 3c-e).

Variability in climate and trade patterns over the simulation period played a key role in the modelled invasion. Climate variability had a greater effect on the seedbank than the adult population, the latter being buffered by the persistent seedbank (Fig. 4a). However climate trends caused average adult

This article is protected by copyright. All rights reserved. 
fecundity to increase over time (Spearman's $\rho=0.309, P=0.016$ ), especially after 1980 (Fig. 4b). Planting seed imports from the native range peaked around 1990, while releases because of trade within Europe increased over time (Fig. 1a) which, in parallel with the growing invasion, increased the importance of the invaded range for generating new colonisations (Fig. 4c).

\section{Model validation}

Comparison with independent pollen monitoring station data suggested our model predicted well the changing distribution of ragweed at a European scale. The temporal trend in normalised annual Ambrosia pollen counts from 1995-2010 was strongly correlated to the simulated trend in ragweed population-fecundity (Spearman's $\rho=0.694, P=0.004$ ) (Fig 5a). There was also a strong spatial correlation between pollen counts in 2010 and the simulated population sizes (Spearman's $\rho=0.720$, $P<0.001$ ), which was even stronger within the 'good data' region (see Fig. 2) where ragweed was most well-recorded $(\rho=0.804, P<0.001)$ (Fig. 5b).

\section{Hypothetical biosecurity simulations}

Simulations with historical biosecurity measures had a greater effect on the extent of ragweed's modelled invasion if the action was initiated earlier in the invasion (Fig. 6). The importance of the bird seed pathway was illustrated when comparing the scenario in which biosecurity applied to both pathways with the more realistic scenario where only the planting seed pathway was controlled (Fig. 6). Preventing introductions through both pathways caused a much greater reduction in ragweed invasion than when only the planting seed pathway was targeted.

The effect of simplifying the model by removing the anthropogenic transport process on model discrimination accuracy was also calculated. Biosecurity on both pathways starting in 1950 markedly reduced the AUC values (ragweed record vs absence $\triangle \mathrm{AUC}=-0.056$, large vs casual record $\triangle \mathrm{AUC}=-0.112$, casual vs absence $\Delta \mathrm{AUC}=-0.055)$ indicating that repeated introduction through trade contributed

towards the fit of the model. 


\section{Discussion}

The model accurately simulated Ambrosia artemisiifolia's current invasive distribution across Europe.

Over the past three decades, growing international trade has increased modelled propagule pressure through the planting and bird seed trade pathways, but with a shift in dominance from native sources to importation from invaded countries. In parallel, the model indicates that the recent trend for warmer summers has increased climatic suitability for ragweed invasion. These model outputs coincide with the period in which ragweed has rapidly extended its range and impacts in southeast Europe and started to establish isolated populations further north (Bullock et al., 2012, Déchamp et al., 2009, Hodisan, 2011, Smolik et al., 2010) supporting the hypothesis that trade and recent climate change have driven ragweed's invasion.

More generally, we consider that our model contains a number of biologically-important features not present in previous computational models for biological invasions, including those for ragweed. From the broad-scale screening perspective (Gallien et al., 2010), ragweed's potentially-invaded region has been modelled with statistical species distribution models (Cunze et al., 2013, Essl et al., 2015, Essl et al., 2009) as well as newer process-based distribution models (Chapman et al., 2014, Hamaoui-Laguel et al., 2015, Storkey et al., 2014). Our model advances beyond these, and equivalent models for other species, by resolving the niche through the dynamic simulation of invasive spread in a changing environment. Other 'hybrid' invasion models also have coupled niche and dispersal models to predict spread (Gallien et al., 2010, Merow et al., 2011), including some for ragweed colonisation in central Europe (Richter et al., 2013a, Richter et al., 2013b, Smolik et al., 2010, Vogl et al., 2008). However, these models simulate spread from an existing invasive distribution, while the model presented here represents the transport and release process mechanistically - incorporating multiple trade pathways as a driver of unintentional introduction and long-distance dispersal at continental scales.

This turned out to be extremely important for explaining ragweed's distribution pattern (Fig. 2). For example, the apparent colonization of the Netherlands is qualitatively different from that further south, the former being driven by repeated introduction but poor persistence (Fig. 3). This finding is 
validated by pollen monitoring stations indicating a lack of pollen production from Netherlands (Hamaoui-Laguel et al., 2015, Prank et al., 2013). Therefore, unless the roles of transport and release process are explicitly represented in generating the observed distribution, models may over-estimate ragweed's climate tolerance. Although our model was developed for the trade pathways through which ragweed disperses, an association between invasion and trade in specific commodities is by no means unique to ragweed (Hulme, 2009, Seebens et al., 2013). For example, the ladybird Harmonia axyridis is known to have been inadvertently transported to previously uninvaded countries in consignments of fruit, vegetables, flowers and timber (Brown et al., 2011). Therefore approaches similar to the one developed here, but using trade flows of relevant commodities, should prove useful for predicting the spread of other species.

Indeed, the main novelty of the work presented here was the integration of a mechanistic model for propagule pressure from trade networks with the invasive spread model. Long-distance anthropogenic transport processes have largely been ignored in models for invasive spread, despite much evidence that propagule pressure is of major importance in explaining biological invasions (Lockwood et al., 2005, Seebens et al., 2013). For ragweed, previous studies show that signals of repeated introduction are evident in the genetic diversity of established populations (Gaudeul et al., 2011) and distribution records from regions unsuitable for population establishment (Chapman et al., 2014, Cunze et al., 2013). Here, we used historical bilateral trade flow data for planting and bird seed commodities to define a simple pathway model for ragweed transport and release. The model estimated propagule pressure from both native seed sources and, as simulations progressed, invaded ones. This allowed us to model introductions from the native range as well as long-distance dispersal via trade networks in the invaded continent. Ongoing globalisation of trade in combination with changes in the climate have been identified as increasing the risk for new plant invasions (Bradley et al., 2011). However to our knowledge, this is the first invasion model to capture such an interaction, as a historical decline in import from the native range was compensated by an increase in intra-European trade and its increasing contamination by ragweed seed as the species rapidly spread. Furthermore, the structure of the trade network played a key role in the simulated invasion. For example, north-eastern Europe was 
historically relatively isolated from the native range in terms of the seed trade, but imports of seed commodities from invaded parts of Europe increased propagule pressure for invasion of this region (Fig. 3d).

This study also demonstrates the important role of modelling in investigating management measures for the control of invasive species (Richter et al., 2013b). We investigated the effectiveness of biosecurity measures (i.e. precautions against the introduction of ragweed seed)_targeting the two major trade pathways for ragweed dispersal - planting seed and bird seed. The simulations showed that both pathways were important in driving spread and that biosecurity was most effective when targeting both introduction routes at an early stage of the invasion. This may explain why ragweed has continued to invade Europe rapidly over recent decades. Despite improved biosecurity measures targeting planting seeds, such as several European Union seed certification regulations (Winge, 2012), high levels of contamination of bird seed remain. A recent review of 12 European studies found 58\% of samples were contaminated and had a mean of 142 ragweed seeds $\mathrm{kg}^{-1}$ (EFSA Panel on Contaminants in the Food Chain (CONTAM) et al., 2010). Therefore the real situation may be similar to our simulations of biosecurity for the planting seed pathway beginning only around 2000, which had virtually no effect on the simulated invasion by 2010. If so, then we can speculate that the areas of northwest Europe receiving the largest amounts of imported bird seed (Fig. 3e) may be most vulnerable to rapid invasion if future climate change increases their suitability for ragweed. We did not use our model to simulate this directly (as this would require gridded time series projections of future climate, land use and global trade), but projections of the model's climatic suitability index $F$ under 2050 climate scenarios from IPCC AR5 suggest those areas will experience large increases in suitability (Fig. S4). This is also true for northeast Europe (Fig. S4) but the trade data suggests this region has lower propagule pressure from bird seed (Fig. 3e), so colonisation may take longer.Our model was developed to be as simple as possible to capture a range of known interacting drivers of ragweed invasion without excessive complexity and an associated loss of tractability. To represent transport and release through two trade pathways, population dynamics, the climatic niche and anthropogenic neighbourhood dispersal we used only 12 free parameters. Inevitably this means that 
all the modelled processes are simplified representations. Nevertheless we consider that the model captured the essence of important features of the invasion, including reproducing the complex current non-equilibrium distribution through an interaction between dynamic climate and trade drivers. There will always be large uncertainty in the predictions of any simulation model of the type used here (Hamaoui-Laguel et al., 2015), especially when there are limited data on the modelled processes so that parameterisation must rely heavily on fitting to distribution data from a wide range of sources of varying quality (Fig. 2). We attempted to account for this by differentiating between regions where ragweed is known to be highly invasive compared to those where it is only casual, and by giving greater weighting to the calibration data from well-recorded countries (the 'good data' region in Fig. 2). Nevertheless we acknowledge that this is large source of uncertainty in the model. Therefore, further model development would clearly benefit from greater empirical parameterisation. Likewise, the calibration would be more precise if accurate snapshots of the European distribution over time were available, as is currently the case for some regions (Richter et al., 2013b, Vogl et al., 2008).

However, a strength of this study is that we were able to validate our model outputs with airborne pollen monitoring data, which was fully independent of the distribution data used for calibration. This showed that the model explained much of the variation in the overall increasing trend in ragweed pollen levels across Europe over 16 years and the spatial pattern of pollen counts in 2010. Many processes not captured in the current model will affect pollen data, such as the production, emission phenology, transport and deposition of pollen grains (Prank et al., 2013). Nevertheless we showed that the level of modelled invasion in the landscape surrounding the pollen stations was strongly correlated to the observed pollen counts. We emphasise that the purpose of this model is not to provide input to pollen transport models or to yield specific details of ragweed invasion for specific locations. Rather we aimed to develop a model that produces an overview of the invasion at a continental scale, for which we consider we were successful.

We conclude that models for species invasion would benefit from integrating mechanistic pathway models for transport through trade networks with invasive spread models based on demography and dispersal. Ultimately such integrated models could predict where the next invasive species are likely

This article is protected by copyright. All rights reserved. 
to be introduced and how quickly they may spread. In particular, they can inform the targeting of surveillance and rapid eradication responses during the early stages of invasion, when the substantial costs of invasive non-native species can still be reduced.

\section{Acknowledgements}

DC and JMB were funded by the European Commission under ENV.B2/ETU/2010/0037 and the Natural Environment Research Council (via National Capability funding to the Centre for Ecology \& Hydrology, project NEC05100). The authors would like to thank the many contributors of ragweed distribution data. In addition to data contributed by the co-authors, ragweed pollen data were kindly provided by Michel Thibaudon, Andreja Kofol Seliger, Barbara Stjepanović, Renata Peternel, Nicoleta Ianovici, Jana Ščevková, Alexander Prikhodko, Elena Severova, Regula Gehrig (Federal Office of Meteorology and Climatology MeteoSwiss), Raina Yankova and the managers of the AIA (Italian Association of Aerobiology) pollen monitoring centres: Fabrizio Ottoboni, Susanna Voltolini, Giuseppe Ronchi, Luigi Giovanni Cremonte, Guido Marcer, Anna Bordin, Maria Russo, Alberto Pini, Anna Molinari, Angela Sangiuolo, Augusto Arsieni, Salvatore Circolone, Clara Scippa, Antonio Graziani, Daniele Berra, Elena Chiodini, Vincenzo Patella, Loretta Pace, Consolata Siniscalco, Luisella Reale. We acknowledge the E-OBS dataset from the EU-FP6 project ENSEMBLES (http://ensembles-eu.metoffice.com) and the data providers in the ECA\&D project (http://www.ecad.eu).

\section{References}

Afonin A, Greene S, Dzyubenko N, Frolov A (2008) Interactive agricultural ecological atlas of Russia and neighboring countries. Economic plants and their diseases, pests and weeds. pp Page, http://www.agroatlas.ru.

Bassett IJ, Crompton CW (1975) Biology of Canadian Weeds. 11. Ambrosia artemisiifolia L. and A. psilostachya Dc. Canadian Journal of Plant Science, 55, 463-476.

This article is protected by copyright. All rights reserved. 
Beaumont MA (2010) Approximate Bayesian computation in evolution and ecology. Annual Review of Ecology, Evolution, and Systematics, 41, 379-406.

Bradley BA, Blumenthal DM, Early R et al. (2011) Global change, global trade, and the next wave of plant invasions. Frontiers in Ecology and the Environment, 10, 20-28.

Brown PJ, Thomas C, Lombaert E, Jeffries D, Estoup A, Lawson Handley L-J (2011) The global spread of Harmonia axyridis (Coleoptera: Coccinellidae): distribution, dispersal and routes of invasion. BioControl, 56, 623-641.

Bullock JM, Chapman DS, Schafer S et al. (2012) Assessing and controlling the spread and the effects of common ragweed in Europe, Final report to European Commission.

Chapman DS, Haynes T, Beal S, Essl F, Bullock JM (2014) Phenology predicts the native and invasive range limits of common ragweed. Global Change Biology, 20, 192-202.

Chauvel B, Dessaint F, Cardinal-Legrand C, Bretagnolle F (2006) The historical spread of Ambrosia artemisiifolia L. in France from herbarium records. Journal of Biogeography, 33, 665-673.

Chipperfield JD, Holland EP, Dytham C, Thomas CD, Hovestadt T (2011) On the approximation of continuous dispersal kernels in discrete-space models. Methods in Ecology and Evolution, 2, $668-681$

Csontos P, Vitalos M, Barina Z, Kiss L (2010) Early distribution and spread of Ambrosia artemisiifolia in Central and Eastern Europe. Botanica Helvetica, 120, 75-78.

Cunze S, Leiblein MC, Tackenberg O (2013) Range expansion of Ambrosia artemisiifolia in Europe is promoted by climate change. ISRN Ecology, 2013, 9.

This article is protected by copyright. All rights reserved. 
Déchamp C, Méon H, Reznik S (2009) Ambrosia artemisiifolia L. an invasive weed in Europe and adjacent countries: the geographical distribution (except France) before 2009. In: Ambroisie: The first international ragweed review. (eds Déchamp C, Méon H) pp Page. Saint-Priest, France, AFEDA.

Dlugosch K, Parker I (2008) Founding events in species invasions: genetic variation, adaptive evolution, and the role of multiple introductions. Molecular Ecology, 17, 431-449.

Efsa Panel on Contaminants in the Food Chain (Contam), Efsa Panel on Dietetic Products Nutrition and Allergies (Nda), (Plh) EPOPH (2010) Scientific Opinion on the effect on public or animal health or on the environment on the presence of seeds of Ambrosia spp. in animal feed. EFSA journal, 8, 1-37.

Essl F, Biró K, Brandes D et al. (2015) Biological Flora of the British Isles: Ambrosia artemisiifolia. Journal of Ecology, n/a-n/a.

Essl F, Dullinger S, Kleinbauer I (2009) Changes in the spatio-temporal patterns and habitat preferences of Ambrosia artemisiifolia during its invasion of Austria. Preslia, 81, 119-133.

Fischer G, Nachtergaele F, Prieler S et al. (2012) Global Agro-Ecological Zones (GAEZ v3. 0)Model Documentation. International Institute for Applied systems Analysis (IIASA), Laxenburg. Rome, Italy: Austria and the Food and Agriculture Organization of the United Nations (FAO).

Gallien L, Münkemüller T, Albert CH, Boulangeat I, Thuiller W (2010) Predicting potential distributions of invasive species: where to go from here? Diversity and Distributions, 16, 331342.

This article is protected by copyright. All rights reserved. 
Gaudeul M, Giraud T, Kiss L, Shykoff JA (2011) Nuclear and chloroplast microsatellites show multiple introductions in the worldwide invasion history of common ragweed, Ambrosia artemisiifolia. PLoS ONE, 6, e17658.

Gilbert M, Grégoire JC, Freise J, Heitland W (2004) Long-distance dispersal and human population density allow the prediction of invasive patterns in the horse chestnut leafminer Cameraria ohridella. Journal of Animal Ecology, 73, 459-468.

Grimm V, Revilla E, Berger U et al. (2005) Pattern-oriented modeling of agent-based complex systems: lessons from ecology. Science, 310, 987-991.

Hamaoui-Laguel L, Vautard R, Liu L et al. (2015) Effects of climate change and seed dispersal on airborne ragweed pollen loads in Europe. Nature Clim. Change, advance online publication.

Hargreaves GL, Hargreaves GH, Riley JP (1985) Irrigation water requirements for Senegal river basin. Journal of Irrigation and Drainage Engineering-Asce, 111, 265-275.

Haylock M, Hofstra N, Klein Tank A, Klok E, Jones P, New M (2008) A European daily high-resolution gridded data set of surface temperature and precipitation for 1950-2006. Journal of Geophysical Research: Atmospheres (1984-2012), 113.

Hodgins KA, Rieseberg L (2011) Genetic differentiation in life-history traits of introduced and native common ragweed (Ambrosia artemisiifolia) populations. Journal of Evolutionary Biology, 24, 2731-2749.

Hodisan N (2011) The spreading of Ambrosia artemisiifolia L. in Romania. pp Page, Oradea, Romania, Ministry of Agriculture and Rural Development, Government of Romania.

Hulme PE (2009) Trade, transport and trouble: managing invasive species pathways in an era of globalization. Journal of Applied Ecology, 46, 10-18.

This article is protected by copyright. All rights reserved. 
Lobo JM, Jiménez-Valverde A, Real R (2008) AUC: a misleading measure of the performance of predictive distribution models. Global Ecology and Biogeography, 17, 145-151.

Lockwood JL, Cassey P, Blackburn T (2005) The role of propagule pressure in explaining species invasions. Trends in Ecology \& Evolution, 20, 223-228.

Mack RN, Simberloff D, Mark Lonsdale W, Evans H, Clout M, Bazzaz FA (2000) Biotic invasions: causes, epidemiology, global consequences, and control. Ecological Applications, 10, 689710.

Merow C, Lafleur N, Jr JaS, Wilson AM, Rubega M (2011) Developing dynamic mechanistic species distribution models: Predicting bird-mediated spread of invasive plants across Northeastern North America. The American Naturalist, 178, 30-43.

Müller-Schärer H, Lommen STE, Rossinelli M, Bonini M, Boriani M, Bosio G, Schaffner U (2014) Ophraella communa, the ragweed leaf beetle, has successfully landed in Europe: fortunate coincidence or threat? Weed Research, 54, 109-119.

Neubert MG, Caswell H (2000) Demography and dispersal: calculation and sensitivity analysis of invasion speed for structured populations. Ecology, 81, 1613-1628.

Petermann A (2011) Cartographie Nationale de l'Ambroisie (Ambrosia artemisiifolia L.), France, Ministère du Travail, de l'Emploi et de la Santé.

Petitpierre B, Kueffer C, Broennimann O, Randin C, Daehler C, Guisan A (2012) Climatic niche shifts are rare among terrestrial plant invaders. Science, 335, 1344-1348.

Prank M, Chapman DS, Bullock JM et al. (2013) An operational model for forecasting ragweed pollen release and dispersion in Europe. Agricultural and Forest Meteorology, 182-183, 4353.

This article is protected by copyright. All rights reserved. 
Pyšek P, Richardson DM (2010) Invasive species, environmental change and management, and health. Annual Review of Environment and Resources, 35, 25-55.

Raynor GS, Ogden EC, Hayes JV (1970) Dispersion and Deposition of Ragweed Pollen from Experimental Sources. Journal of Applied Meteorology, 9, 885-895.

Reznik S (2009) Common ragweed (Ambrosia artemisiifolia L.) in Russia: spread, distribution, abundance, harmfulness and control measures. In: Ambroisie: The first international ragweed review. (eds Déchamp C, Méon H) pp Page. Saint-Priest, France, AFEDA.

Richter R, Berger UE, Dullinger S, Essl F, Leitner M, Smith M, Vogl G (2013a) Spread of invasive ragweed: climate change, management and how to reduce allergy costs. Journal of Applied Ecology, 50, 1422-1430.

Richter R, Dullinger S, Essl F, Leitner M, Vogl G (2013b) How to account for habitat suitability in weed management programmes? Biological Invasions, 15, 657-669.

Seebens H, Gastner M, Blasius B (2013) The risk of marine bioinvasion caused by global shipping. Ecology Letters, 16, 782-790.

Skjøth C, Šikoparija B, Jäger S, Network EaN (2013) Pollen Sources. In: Allergenic Pollen. (eds Sofiev M, Bergmann K-C) pp Page., Springer Netherlands.

Skjøth CA, Smith M, Šikoparija B et al. (2010) A method for producing airborne pollen source inventories: An example of Ambrosia (ragweed) on the Pannonian Plain. Agricultural and Forest Meteorology, 150, 1203-1210.

Smith M, Cecchi L, Skjøth CA, Karrer G, Šikoparija B (2013) Common ragweed: A threat to environmental health in Europe. Environment International, 61, 115-126.

This article is protected by copyright. All rights reserved. 
Smolik MG, Dullinger S, Essl F et al. (2010) Integrating species distribution models and interacting particle systems to predict the spread of an invasive alien plant. Journal of Biogeography, $\mathbf{3 7}$, 411-422.

Storkey J, Stratonovitch P, Chapman DS, Vidotto F, Semenov MA (2014) A process-based approach to predicting the effect of climate change on the distribution of an invasive allergenic plant in Europe. PLoS ONE, 9, e88156.

Thibaudon M, Šikoparija B, Oliver G, Smith M, Skjøth CA (2014) Ragweed pollen source inventory for France - The second largest centre of Ambrosia in Europe. Atmospheric Environment, 83, $62-71$.

Thuiller W, Richardson DM, Pyšek P, Midgley GF, Hughes GO, Rouget M (2005) Niche-based modelling as a tool for predicting the risk of alien plant invasions at a global scale. Global Change Biology, 11, 2234-2250.

Vilà M, Espinar JL, Hejda M et al. (2011) Ecological impacts of invasive alien plants: a meta-analysis of their effects on species, communities and ecosystems. Ecology Letters, 14, 702-708.

Vogl G, Smolik M, Stadler LM et al. (2008) Modelling the spread of ragweed: Effects of habitat, climate change and diffusion. European Physical Journal-Special Topics, 161, 167-173.

Willemsen RW (1975) Effect of stratification temperature and germination temperature on germination and the induction of secondary dormancy in common ragweed seeds. American Journal of Botany, 62, 1-5.

Winge T (2012) A Guide to EU Legislation on the Marketing of Seed and Plant Propagating Material in the Context of Agricultural Biodiversity. pp Page, Lysaker, Norway, Fridtjof Nansen Institute.

This article is protected by copyright. All rights reserved. 
Yemshanov D, Mckenney DW, Pedlar JH, Koch FH, Cook D (2009) Towards an integrated approach to modelling the risks and impacts of invasive forest species. Environmental Reviews, 17, $163-178$.

\section{Supporting Information captions}

Figure S1. A simplified overview of the anthropogenic transport and release model.

Figure S2. Scheduling of events in the simulation model for invasive species introduction and spread.

Figure. S3. Map of the pollen stations used for model validation.

Figure S4. Projections of ragweed fecundity to the 2050s under a range of climate change scenarios.

This article is protected by copyright. All rights reserved. 
Table 1. Calibration of the ragweed invasion model. Using random parameterisations drawn from within the specified ranges, 10000 simulations of the model were performed and the best-fitting $0.5 \%$ of parameterisations were selected. As a measure of importance to model fit, well-fitting parameter distributions were compared to their uniform proposal distribution using the Kolmogorov-Smirnov statistic $D . D$ varies from 0 to 1 , with larger values indicating divergence from the proposal distribution and a greater importance.

\begin{tabular}{|c|c|c|c|c|c|}
\hline & Parameter & Meaning & $\begin{array}{l}\text { Uniform } \\
\text { proposal } \\
\text { distribution }\end{array}$ & $\begin{array}{l}\text { Median in best } 0.5 \% \text { of } \\
\text { parameterisations }\end{array}$ & $\begin{array}{l}\text { Importance } \\
\text { (D) }\end{array}$ \\
\hline \multirow{3}{*}{ 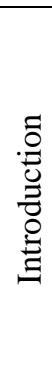 } & $\Gamma_{U S A}$ & $\begin{array}{l}\text { Cropland contamination rate } \\
\text { for USA. }\end{array}$ & $0.1-0.8$ & 0.59 & 0.280 \\
\hline & $v$ & $\begin{array}{l}\text { Increase in colonisation with } \\
\text { planting seed propagule } \\
\text { pressure to cropland. }\end{array}$ & $0-10$ & 7.53 & 0.328 \\
\hline & $\kappa$ & $\begin{array}{l}\text { Increase in colonisation with } \\
\text { bird seed propagule pressure } \\
\text { to urban areas. }\end{array}$ & $0-300$ & 212 & 0.255 \\
\hline \multirow{2}{*}{$\begin{array}{l}\tilde{U} \\
. \tilde{\Xi} \\
\tilde{\Xi} \\
\tilde{\Xi}\end{array}$} & $\lambda$ & $\begin{array}{l}\text { Increase in adult } \\
\text { establishment with seedbank } \\
\text { size. }\end{array}$ & $2-4$ & 3.56 & 0.487 \\
\hline & $\alpha$ & Seed bank persistence rate. & $0.5-0.8$ & 0.71 & 0.313 \\
\hline \multirow{6}{*}{ 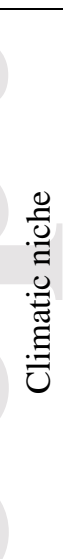 } & $b_{W}$ & $\begin{array}{l}\text { Slope of winter temperature } \\
\text { on fecundity. }\end{array}$ & $-3--1$ & -2.14 & 0.200 \\
\hline & $a_{W}$ & $\begin{array}{l}\text { Winter temperature } \\
\text { inflexion point. }\end{array}$ & $2-5$ & 3.97 & 0.197 \\
\hline & $b_{S}$ & $\begin{array}{l}\text { Slope of summer } \\
\text { temperature on fecundity. }\end{array}$ & $1-3$ & 2.15 & 0.185 \\
\hline & $a_{S}$ & $\begin{array}{l}\text { Summer temperature } \\
\text { inflexion point. }\end{array}$ & $18-21$ & 18.2 & 0.752 \\
\hline & $b_{M}$ & $\begin{array}{l}\text { Slope of moisture on } \\
\text { fecundity. }\end{array}$ & $30-40$ & 35.8 & 0.151 \\
\hline & $a_{M}$ & Moisture inflexion point. & $0.2-0.3$ & 0.21 & 0.724 \\
\hline 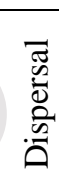 & $\mu$ & $\begin{array}{l}\text { Increase in colonisation with } \\
\text { neighbourhood propagule } \\
\text { pressure. }\end{array}$ & $1-2$ & 1.76 & 0.433 \\
\hline
\end{tabular}

This article is protected by copyright. All rights reserved. 
Figure 1. (a) Recent trends in total imports of bird and planting seed to the modelled region from the native range (USA) and within Europe (data available for planting seed only). (b) The network in seed trade for countries in the model, averaged for 1992-2010. Darker shading indicates higher import rates per unit area of urban cover for bird seed (labelled) or cropland for planting seed, on a logarithmic scale. Country abbreviations are labelled alternately on either side of the plot, following UN ISO 3166-1 alpha-3 codes with XK for Kosovo.

Figure 2. Ragweed's approximate 1991-2010 distribution in the modelled domain. We differentiated between presence records in regions with large and damaging populations versus those with small or casual populations, and also between countries where the species was considered to be recorded well or poorly. The graticule intervals are $20^{\circ}$ longitude and $10^{\circ}$ latitude.

Figure 3. Calibrated model outputs averaged over five simulations of the top $0.5 \%$ of parameterisations and from 1991-2010.

Figure 4. The modelled ragweed invasion is driven by climate and trade. (a) Modelled relative population growth of adults and the seedbank, averaged over the $0.5 \%$ top model parameterisations. (b) Time series of the mean fecundity index in the modelled region from the top parameterisations, showing a significant increase in climatic suitability over time (generalised additive model [GAM], $P=0.004, \mathrm{R}^{2}=0.188$ ). (c) Stacked time series of simulated introductions by all trade pathways, where shaded areas represent the numbers of introduction. (d) Boxplots of the average annual modelled probabilities of introduction from all trade pathways and neighbourhood seed dispersal into a grid cell with different population statuses (see Fig. 2). Outlying observations are omitted for clarity.

Figure 5. Validation of the model by comparison against independent data on temporal and spatial trends from ragweed pollen monitoring. (a) The observed temporal trend in total annual pollen counts over 16 years at 47 monitoring stations (between 11 and 45 stations in each year, because of missing data), plotted against the trend in simulated ragweed population-fecundity $(N F)$ in the grid cells containing the same stations. For comparison, both trends are normalised to sum to unity. (b) The observed total ragweed pollen counts at 92 stations in 2010 plotted against the mean simulated 
population fecundity in 2010 in the grid cells containing each station. Points represent the countries of each station (abbreviated following UN ISO 3166-1 alpha-3 codes) with black shading for the 'good data' region and grey shading for the 'poor data' region (see Fig. 2).

Figure 6. Results from historical biosecurity simulations, in which introduction through both trade pathways or only the planting seed pathway is prevented after a specific year. The plot shows the ragweed adult population size in 2010 relative to simulations in which no biosecurity is implemented.
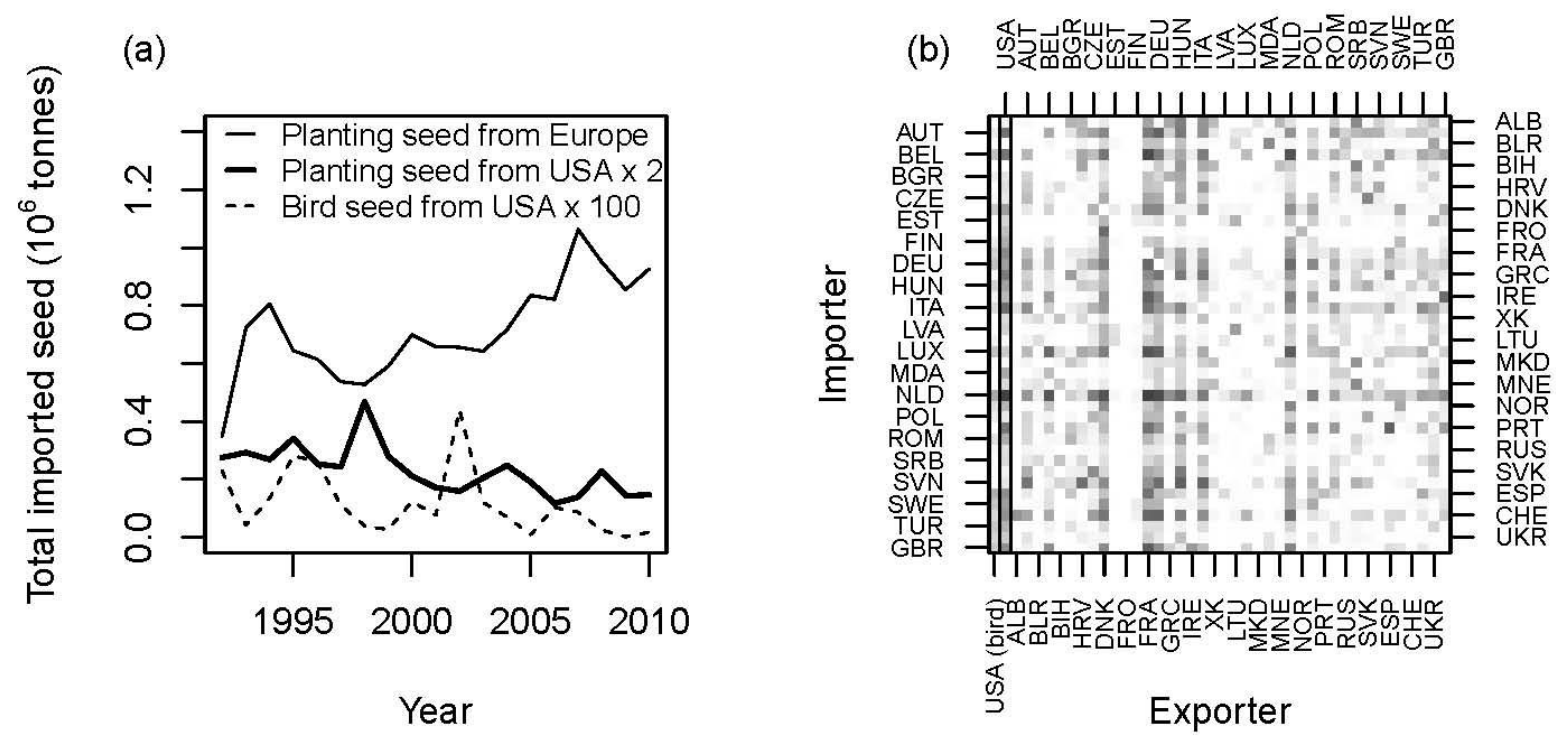

This article is protected by copyright. All rights reserved. 


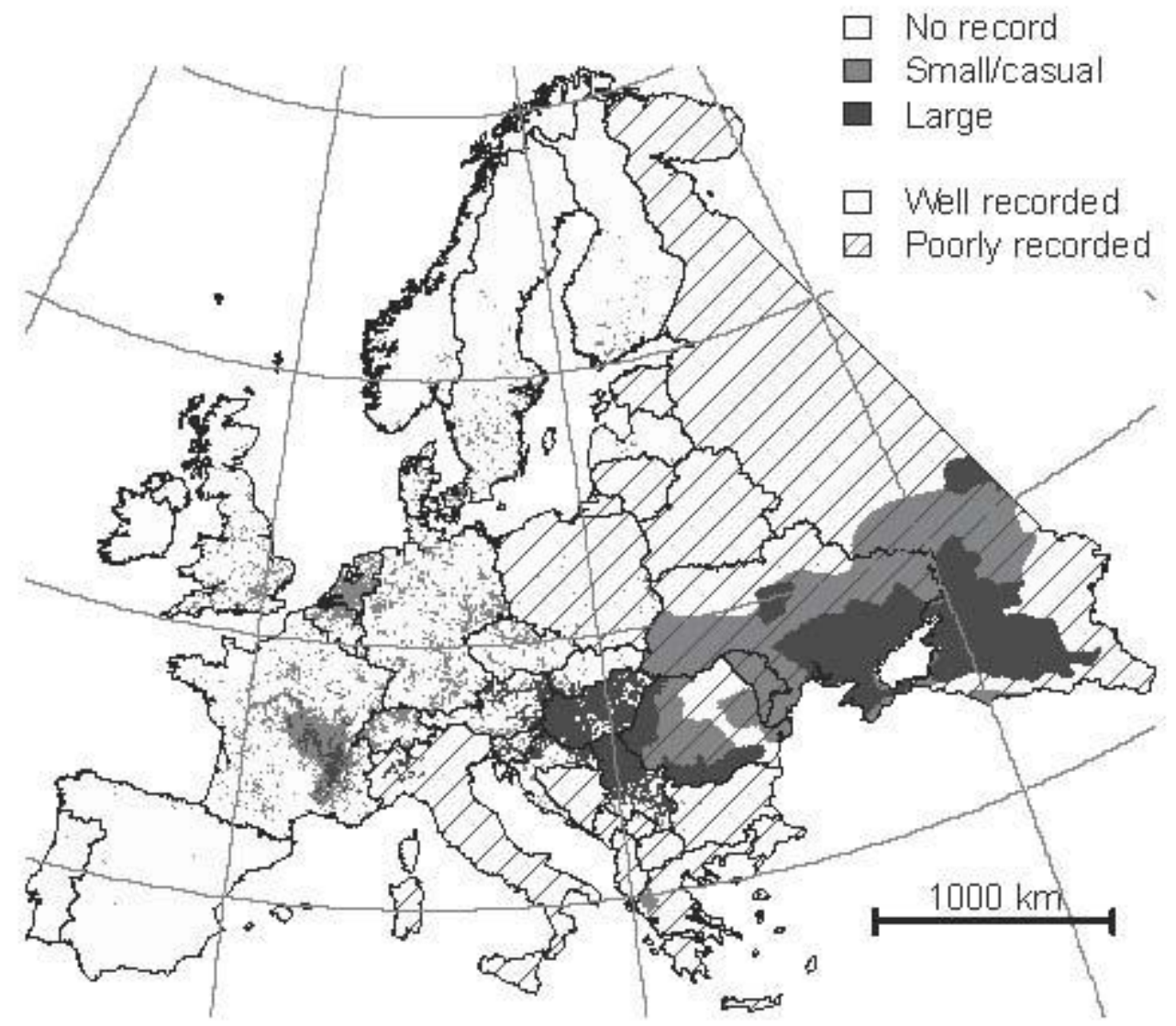

This article is protected by copyright. All rights reserved. 
(a) Adult population

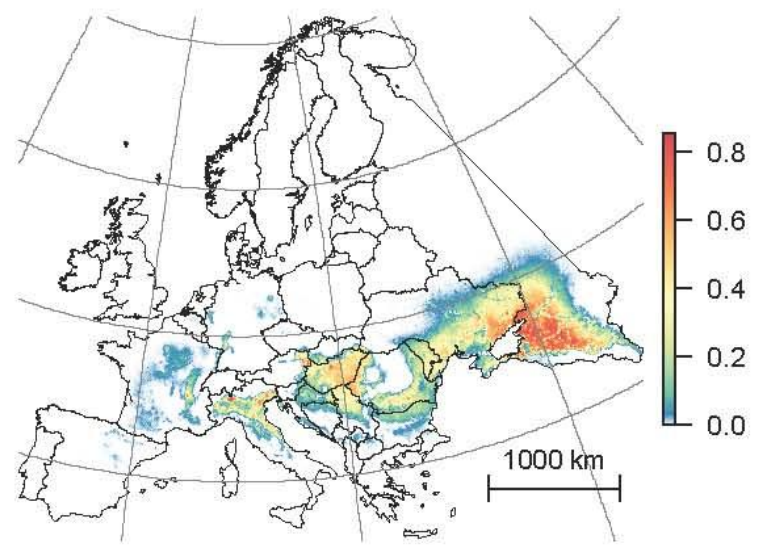

(c) Introduction (Planting seed from native)

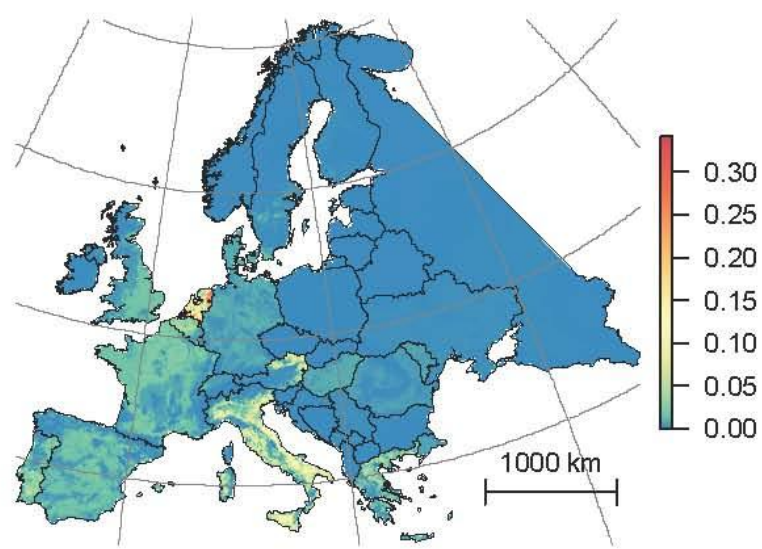

(e) Introduction (Bird seed from native)

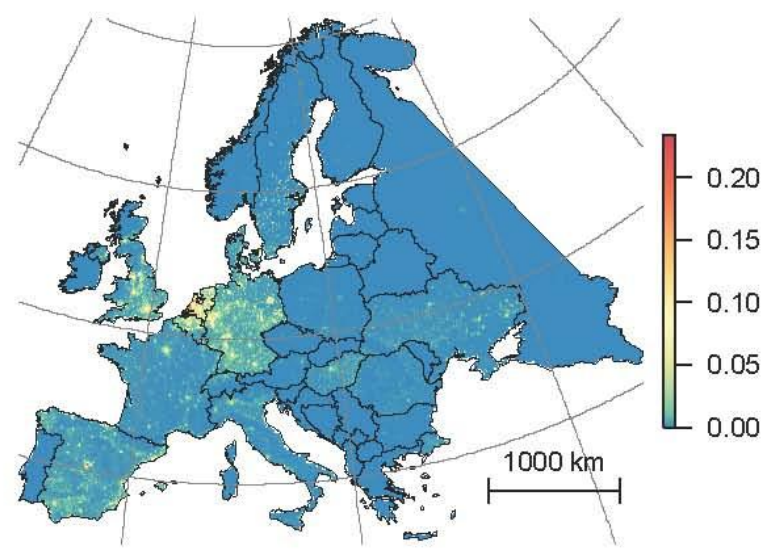

(b) Climatic suitability $F$

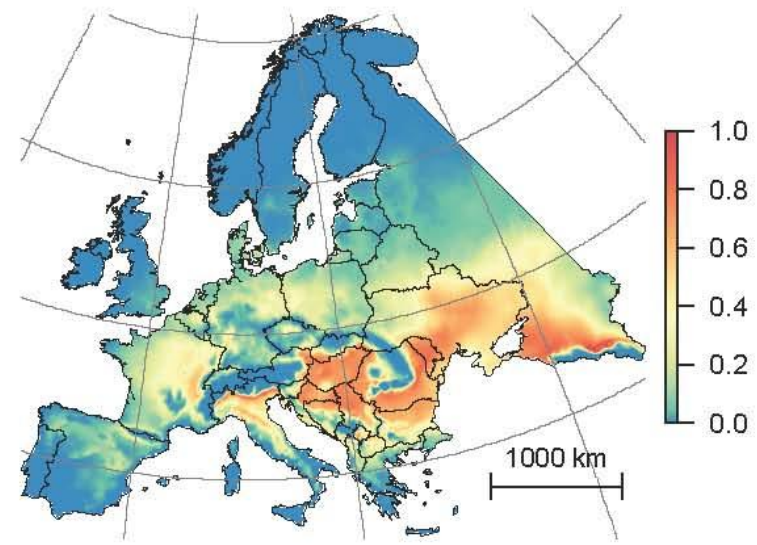

(d) Introduction (Planting seed from invaded)

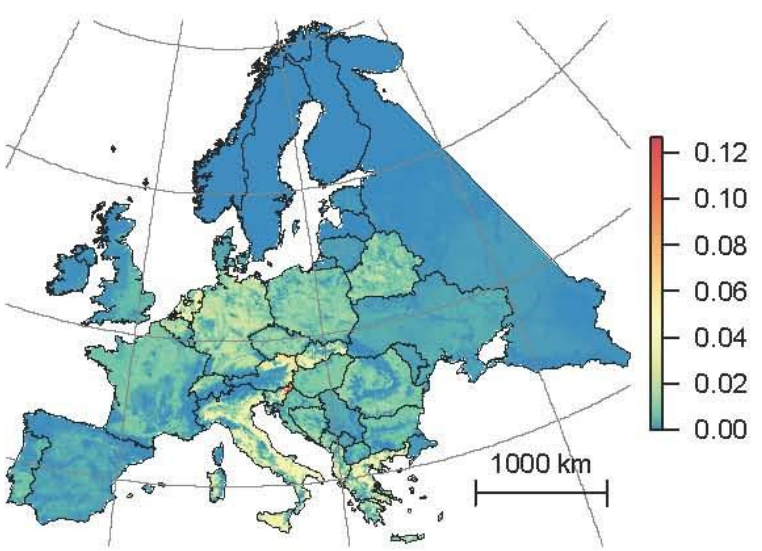

(f) Neighbourhood dispersal

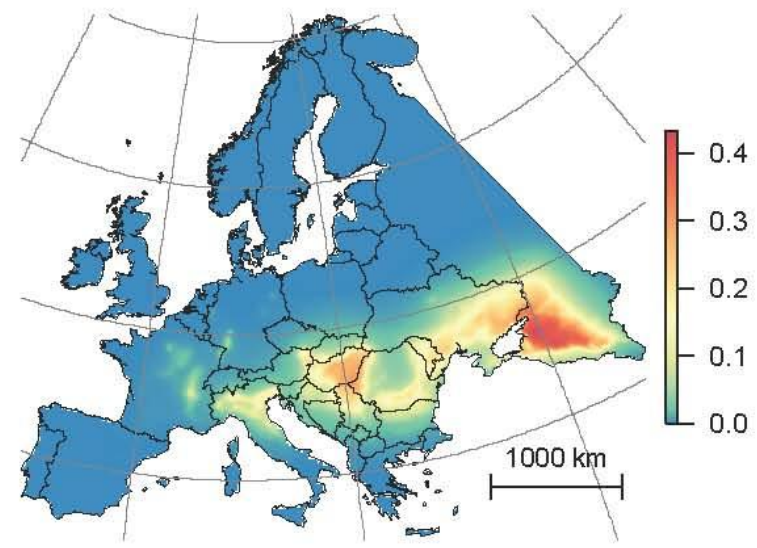

This article is protected by copyright. All rights reserved. 
(a)

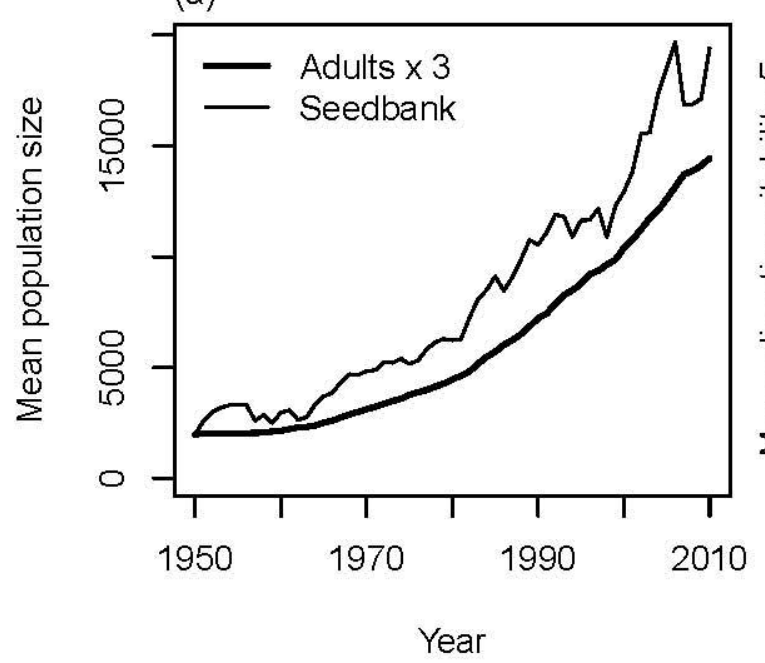

(b)

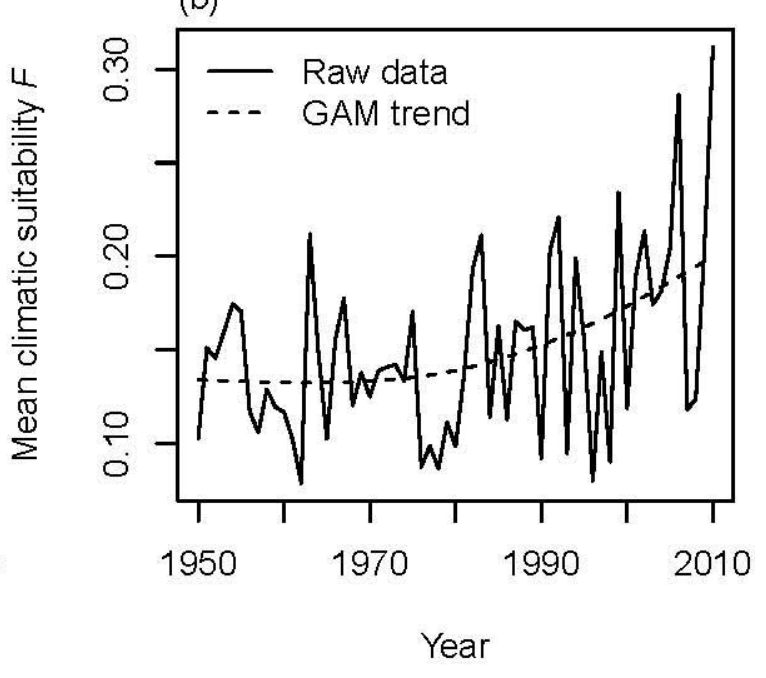

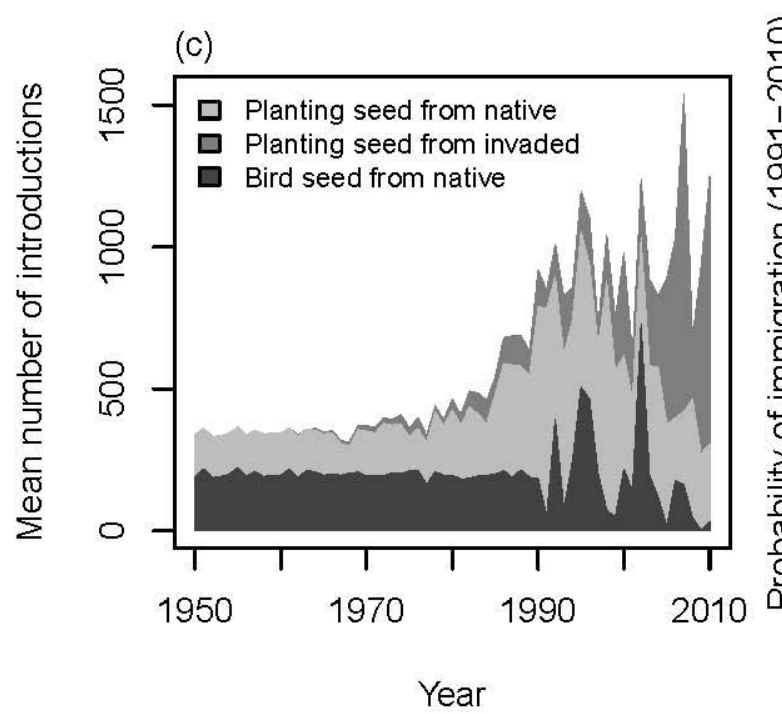

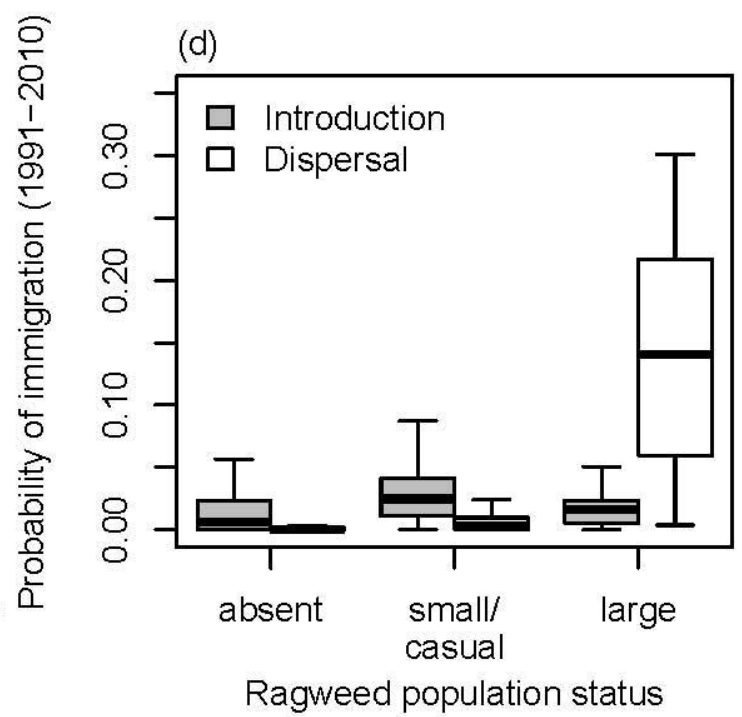

This article is protected by copyright. All rights reserved. 
(a)
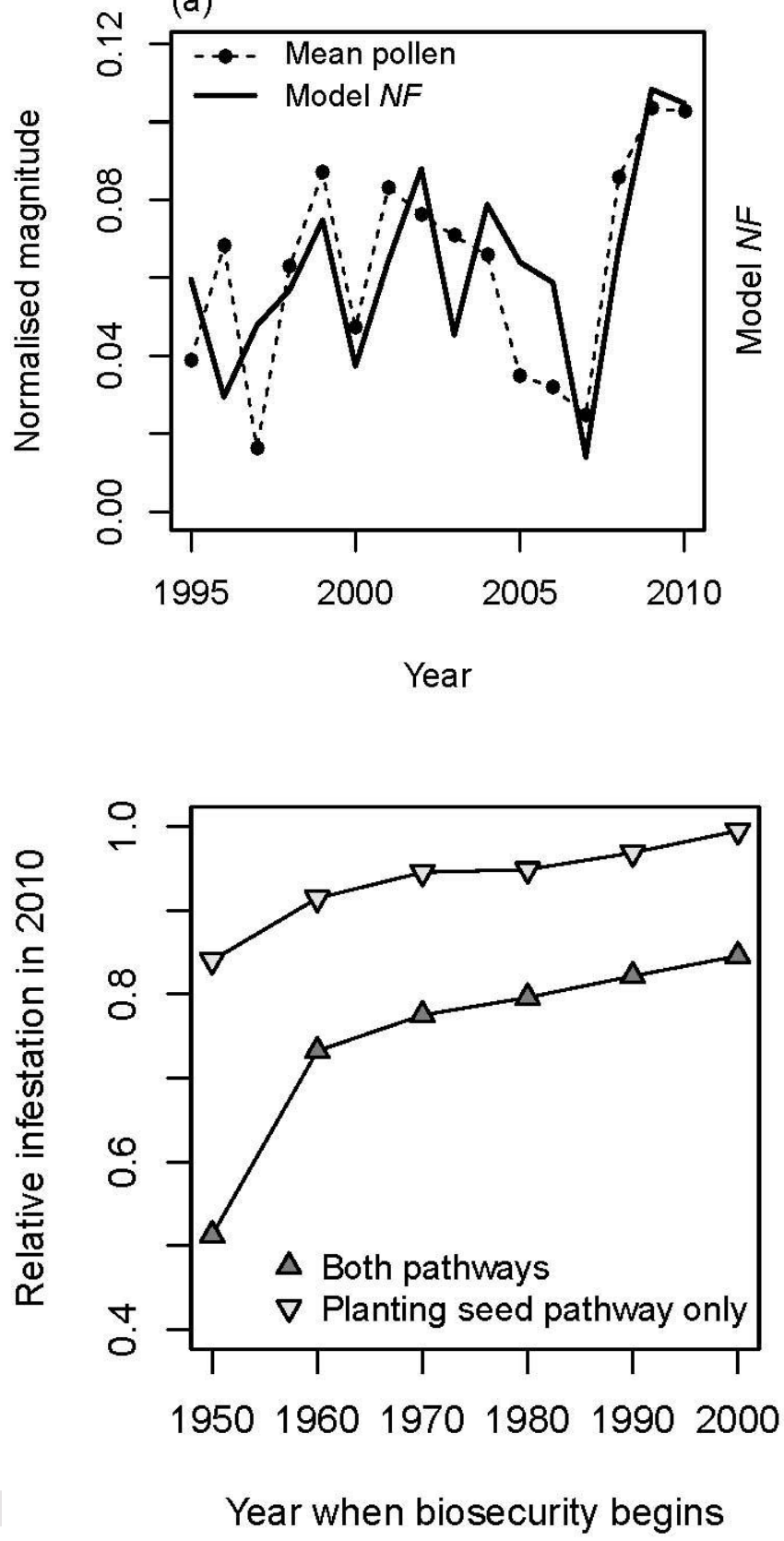

(b)

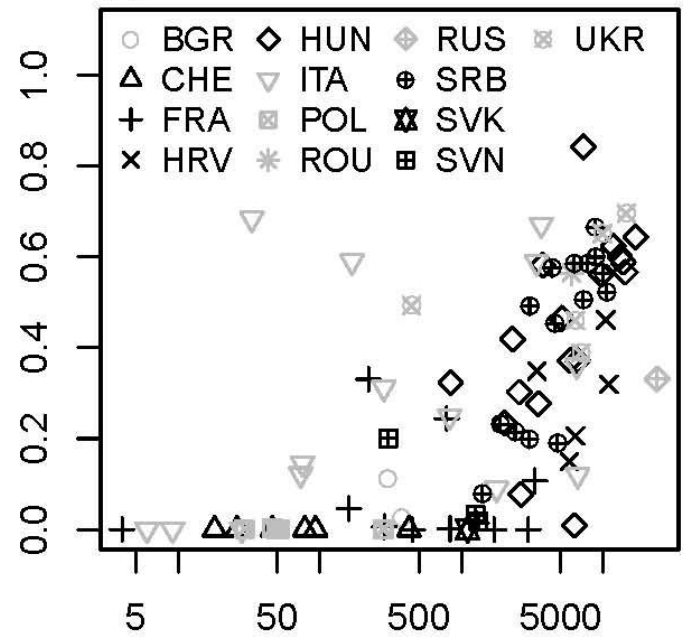

Observed pollen count 